\title{
PROSTATIC SURGERY
}

\author{
By T. J. D. LaNe, M.D. \\ Surgeon to Meath Hospital, Dublin
}

This communication presents a critical survey of the developments in the treatment of prostatic obstruction since they were last reviewed by Clifford Morson (1935) in 1935. The opportunity is also taken to give a fairly detailed account of our present practice at the Urological Department of the Meath Hospital.

While the last 14 years have indeed been vintage years for the urologist, unfortunately they have not brought us nearer the discovery of the cause of bladder neck obstruction, whether this be adenomatous, ${ }^{*}$ fibrous, or malignant. But when Huggins (194I) showed the dependence of the prostatic cancer cell on male sex hormone, although he did not find the cause of these tumours, he certainly transformed our outlook on the disease and brought hope to the hopeless. While the theory of hormone imbalance is an attractive way of explaining the development of the adenomatous gland, it remains a hypothesis without the possibility of reasonable practical application. When we really know the cause of this lesion, medicine, both preventive and therapeutic, may well achieve a resounding triumph. Until this happens the only method of treating established prostatic obstruction due to adenomatous or fibrous disease, and still in some cases to cancer, is by operation.

Until operation becomes necessary we can usually only help the patient by advice ; we council caution in conviviality, the avoidance of delay in emptying the bladder, the importance of warmth, and so forth. Undoubtedly the greatest service we can offer is to review the patient's progress every six or twelve months and thereby safeguard him against serious chronic obstruction developing without symptoms. While in some cases symptoms and obstruction remain minimal for years and death eventually is due to some other cause, in others the lesion may be quietly progressive. Because prediction of the future is uncertain, observation is obviously essential.

\footnotetext{
* In default of any other adequate word, ' adenomatous' is used throughout this article to describe the condition of benign prostatic hypertrophy. Its use in no way implies that the condition is considered to be neoplastic.
}

There is no place for radiation or the use of the sex hormones in the treatment of the adenomatous or fibrous prostate. Because of the possibility of latent cancer, the administration of testosterone may not be free from risk and I have never seen it do any objective good. On the other hand the control of such coincidental lesions as diabetes mellitus or urinary infection may greatly benefit the patient.

The questions which arise regarding the various aspects of surgical intervention in prostatic obstruction will be discussed in the following order :-

I. Who should operate ?

2. What are the indications for operation?

3. What pre-operative treatment is required ?

4. What is the treatment of choice for (a) Acute retention? (b) Chronic retention ?

5. What operation should be performed ?

6. What post-operative care should be provided ?

7. What special conditions arise in the case of carcinoma?

\section{Who Should Operate ?}

The answer to this question involves the important decision as to whether the operation of prostatectomy should be carried out by a general surgeon or should be reserved for the urologist. Doyen (I917) declared :- It requires but little knowledge to perform a surgical operation.' There is, however, a vast difference between the mere operator and the skilled and experienced surgeon. In the first flush of success, Millin (1947a) and Wilson Hay (1948) allowed enthusiasm temporarily to overcloud their habitual clear-sightedness and claimed that their operations opened up prostatic surgery for the general surgeon. Unless, without any reason at all, I am to follow them in their short-lived lapse into heresy, the question must at once be amended to who should TREAT these patients? My answer is that they should be treated by urological surgeons, and I believe that in the future more and more of these cases will be so treated. Much of the safety and success of relieving prostatic obstruction depends on team 
work and efficient organization ; these can only be obtained in a unit where several cases are dealt with week in and week out, throughout the year.

\section{What are the Indications for Opera- tion?}

The important question of the proper time and reasons for surgical intervention in prostatic obstruction has lately been brought to the forefront by Millin, McAllister and Kelly (1949). I completely agree with Millin and his associates that in general 'operation should be advised in established prostatic obstruction.' I further agree that the residual urine test as a diagnostic test is obsolete. Observation of the urinary stream, palpation including bimanual palpation of the bladder and, above all, intravenous pyelo-cystography together render this test unnecessary, out-of-date, and dangerous in all but expert hands. While Millin and his colleagues have not defined exactly what they mean by ' established prostatic obstruction,' I have little doubt that they would not differ with me on the following points :-

I. In established prostatic obstruction the decision to operate and the choice and timing of the operation should be reached only after a full and thorough examination of the patient.

2. Established prostatic obstruction includes all patients who are still able to empty their bladders but (a) whose social life is made difficult by ' encores,' frequency or difficulty during the day, or whose nights are made sleepless by the number of times they have to rise, especially if, in these same cases, difficulty has become serious ; (b) whose urinary streams, observed under favourable conditions, are seriously impaired; (c) who are subject to frequent attacks of retention; (d) who are unable to take a drink without getting acute retention, yet are not prepared to abstain from alcohol.

3. In many cases the existence of prostatic obstruction can be established only by intravenous urography. The findings of a cystographic shadow of normal proportions after the patient has been given a fair opportunity of voiding, especially if associated with diverticula or, more important, with dilatation of the lower end of one or both ureters, is diagnostic. Inability to empty the bladder may quite often be detected in a straight film, but urography is essential for a full and proper study.

4. In a patient who, in addition to any obviously overdistended bladder due to marked prostatic obstruction, is also suffering from an extra-urinary lesion which is certain to destroy his life in a few months, then, if interference is compelled by pain or discomfort, the choice lies between endoscopic resection, repeated catheterization or cystostomy.
5. Even in the presence of established prostatic obstruction with an obviously overdistended bladder, operation is inadvisable in the patient with a serious or potentially serious vascular or cardiac lesion, provided there is no pyeloureterectasis.

No attempt will be made to give a full list of the reasons for and against prostatectomy in different circumstances. . Established prostatic obstruction is a useful term, and Millin would not have been attacked by Vernon (1949) and Chapman (1949) for suggesting its earlier treatment by surgery if prostatectomy was limited in practice to urologists. In actual fact this is far from the case, with results that are common knowledge. In spite of this knowledge urology is still fighting for recognition as a speciality in these islands.

\section{What Pre-Operative Treatment is Re- quired ?}

Apart from measures directly concerning the urinary tract, which will be dealt with in the next section, the high average age of prostatic patients makes a thorough investigation of their general clinical condition of the utmost importance. The co-operation of a specially experienced physician is invaluable. We have found medical grading of the patient very helpful, and my medical colleague, Brian Mayne, has kindly contributed this note.

' In order the more accurately to assess a patient's condition pre-operatively, and to enable comparisons to be made between one patient and another as to fitness for operation, it was decided to introduce a grading system. Patients about to undergo operation are therefore placed in one of four grades. In determining the grade, the condition demanding operation is not taken into consideration, but any other disabilities are carefully assessed.

'The grade in which a patient is placed does not necessarily indicate that patient's long-term prognosis. A patient may be put in the lowest grade as a result of a severe infection from which recovery is possible, for example, bilateral lobar pneumonia, or as a result of a condition from which recovery is impossible, for example, gastric carcinoma with widespread secondaries. Thus it is necessary when stating the grade of a patient to give the reason for which the grade was chosen, and also a note as to whether improvement can be expected within a reasonably short time, as a result of which the patient could be re-assessed and might be placed in a higher grade. A statement as to treatment should immediately follow the grade. For example :-

- Med. Grade 4. Auricular fibrillation and severe congestive heart failure. Improvement ex- 
pected in two weeks. Treatment: Digitalis ; salt free diet ; fluid restriction, etc.

'The four grades are distinguished as follows:-

'Grade I. A patient having no disability other than the operable disability.

'Grade 2. A patient having some disability other than the operable disability, but one which is not likely to increase the operative risk appreciably.

'Grade 3. A patient having some disability in addition to the operable disability, which is likely to increase the operative risk appreciably, or which carries in itself a grave prognosis.

'Grade 4. A patient having, in addition to the operable disability, some disability which carries such a grave prognosis at the present as to make operation unjustifiable, or which carries such a grave ultimate prognosis as to make operation unnecessary.

' On receiving the medical grading statement, the surgeon can add it to what he already knows about the patient's operable disability, and can decide the immediate fitness for operation, the advisability ${ }^{\prime}$ of postponing operation, and the necessity for any special treatment or precautions to be undertaken concurrently. with the operative treatment.'

Clifford Morson's reminder that Freyer's mortality rate was 4.7 per cent. was a salutary and an inspiring challenge. In spite of greatly improved anaesthesia, the antibiotics and refinement in technique few today do much better and many not so well. I am convinced that only ceaseless care and attention to detail will effect material improvements in our returns. This applies not only to factors directly affecting the operation or even directly concerning the urinary system, but also to the general clinical condition of the patient. For example, as a result of recent preliminary investigations carried out by Professor W. E. J. Jessop of the Department of Physiology, Royal College of Surgeons in Ireland, ${ }^{*}$ it would appear 'that 3 per cent. of prostatic cases may have diabetes of a sub-clinical grade.' Obviously such cases, if undetected, may develop serious, even fatal, post-operative complications.

A really thorough examination of the patient will take, even with good organization, two or three days. Holding such an examination to be essential, I have not given Wilson Hey's (1945) policy of immediate prostatectomy a crial.

\footnotetext{
* Mr. Lane and Professor W. E. J. Jessop have kindly provided full details of these investigations, which will be sent to anyone interested on application to the Editor.
}

4. What is the Treatment of Choice for (a) Acute Retention ? (b) Chronic Retention ?

\section{(a) Acute Retention}

Some patients reach the urologist with the urethra damaged by the general practitioner's efforts to give relief with the catheter. While the urethra may be badly injured at a single attempt, it is particularly prone to such injury if unskilful catheterization has been repeated over some days. This trouble can only be rectified, and the incidence of strictures lessened, by insistence on gentleness and the use of rubber catheters only. Further, if catheterization is not immediately successful, the bladder should be emptied by the suprapubic insertion of a trocar and cannula or spinal needle. In practice a cannula is much more convenient, because it will empty the bladder so much faster. It is interesting to recall that most authorities when describing tapping of the bladder recommend complete emptying before withdrawing the instrument. Tapping can be repeated three or four times if necessary. A penicillin cover is advisable. Chloromycetin, which has just become available, promises to be a most useful and convenient drug.

\section{(b) Chronic Retention}

Pre-Operative Treatment. With very few exceptions the treatment of chronic retention will be surgical. If the retention is moderate in degree (a residual estimated to be about a pint or less), if renal efficiency is not seriously impaired, if the blood urea is below $100 \mathrm{mgm}$. per cent., if the urinary tract is uninfected and if the patient has a good urinary output (three or more pints per day), no pre-operative treatment is necessary.

If the degree of retention is gross $(30 \mathrm{oz}$. or more), it is my practice to drain the bladder. If such drainage is necessary for only a few days, as is usually the case where renal efficiency is not seriously impaired (blood urea below $150 \mathrm{mgm}$. per cent.), we tie in a No. 15 or No. $18 \mathrm{Ch}$. Tieman catheter. It is general knowledge that while some patients tolerate the catheter (indwelling or intermittent) perfectly well for weeks or even months, others develop a urethritis in a few days. There is no way of forecasting a particular patient's reaction. Because of this, and because all modern operative techniques require the indwelling catheter for at least three or four days, I think it best to ration its pre-operative employment. Accordingly, where for any reason more prolonged drainage is essential, we insert a Malecot catheter through a trocar and cannula $I_{2} \frac{1}{2}$ in. or so above the symphysis and a little to one side of the midline. For some months past we 
have used an 18 French Malecot catheter passed through a 28 French cannula. Mothersill and Morson used an essentially similar technique as long ago as 1921 . In 1943 , Riches described an ingenious and practical method of suprapubic catheterization. It is very interesting to note that both Mothersill and Morson (192I) and also Riches (1943) incise the skin and rectus sheath. The use of a large cannula and small catheter makes for a little extra simplicity, in that it is necessary to incise only the skin. The performance of this little operation has been deliberately limited to the most junior members of the staff of the Urological Department of the Meath Hospital, and they employ it only when they are absolutely certain that they can feel an overdistended bladder. Though stab cystostomy has been condemned by Swift Joly (personal communication) and Millin (1947b), our experience agrees with that of Morson and Riches regarding its safety, even in relatively inexperienced hands. It leaves the anterior surfaces of both bladder and prostate usually in perfect, and always in good, condition for the major attack.

No discussion of cystostomy, however short, could be ended without condemning the all too prevalent practice of doing the 'open' operation through a low vertical midline incision, with the tube inserted immediately above the symphysis pubis. If done as a permanent measure this horrid practice adds greatly to the patient's discomfort. If performed as a prelude to prostatectomy it may render even cystoscopy all but impossible, by causing fibrosis of the suspensory ligament of the penis and thus preventing the downward deflection necessary to pass the instrument into the bladder. Worse still, this cowardly and slovenly bit of ' surgery' too often makes a retropubic prostatectomy impossible and hampers the proper performance of a Freyer. We have not so far tried Sandrey's perineal drainage.

Slow decompression of the bladder was originally described in a rather emotional article by Von Zwalenberg (1920) of America. It was taken up at once by Verne Hunt (1923) and his associates at the Mayo Clinic. In I927 Frank Kidd (1927) praised and developed it. In I93 I Hamilton Bailey (1934) extolled it and devised a special instrument for practising it. The danger of immediate emptying of the chronically overdistended bladder has been stressed more than once by Riches (1944, 1949). Von Zwalenberg's principle is still in vogue throughout Great Britain today.

Almost 20 years ago the workers at the Mayo Clinic tried out a larger series of cases side by side, with and without decompression. The results of their experiment showed that nothing was to be gained by its employment, and since then decompression, as we know it, has not been used by them. In a letter dated May 31, 1949, Dr. Edward Cook wrote :- 'As regards the subject of decompression, we still do not practise it here at this clinic. For almost 20 years now we have not worried about the necessity for gradual decompression in any of these cases. In those patients with a large retention, the catheter is inserted and up to 1,000 or $1,500 \mathrm{cc}$. may be drawn off immediately. If the retention is over this we have on occasions, if the patient's general condition seemed rather poor, removed an additional $500 \mathrm{cc}$. every hour until the bladder is completely emptied. We have experienced no ill results because of this program.'

Since 1938 no patient has been ' decompressed' in my department and my experience tallies with that of the workers at the Mayo Clinic. The case against decompression may be based on the following considerations. No urologist has seen the need to decompress the hydronephrotic kidney; every urologist has seen the hydronephrotic kidney submitted to a plastic operation plus nephrostomy in the morning functioning well, and draining freely in the afternoon of the same day. There might be more sense in advocating decompression if as the result of vesical over-distension the ureteric orifices were patent and gaping, and the pelvis of the ureter in free communication with the bladder. Daily cystoscopic and operative experience teaches us that this is not so. Such free communication is a rare terminal phenomenon. Ordinary everyday pyelographic studies show, in case after case, the obstruction to be in either the juxtavesical or intramural part of the ureter. The exact site is a subject that Professor R. A. Q. O'Meara has commenced to study.

We adopt the Mayo Clinic method of closed drainage, using a modification of the bottle described by Emmett (1937) and made for us by the Genito-Urinary Co., of London (Fig. I). There is a prevalent British superstition that these bottles are apt to become air-locked. We have used them for over ten years without meeting this trouble. By changing the bottles, which hold two pints, at standard times a glance at them will tell the patient's output at any intervening moment. The bottles, their fittings and the connecting tubes are cleaned by a special orderly; they are sterilized by boiling - an operation carried out by the nurses, who use strict aseptic and antiseptic care in disconnecting and reconnecting them to the catheters. Viscocaps are convenient for sealing off the bottles after boiling.

In a patient with marked uraemia, it is very important that an estimation of the alkali reserve should be done when drainage is established, if it 


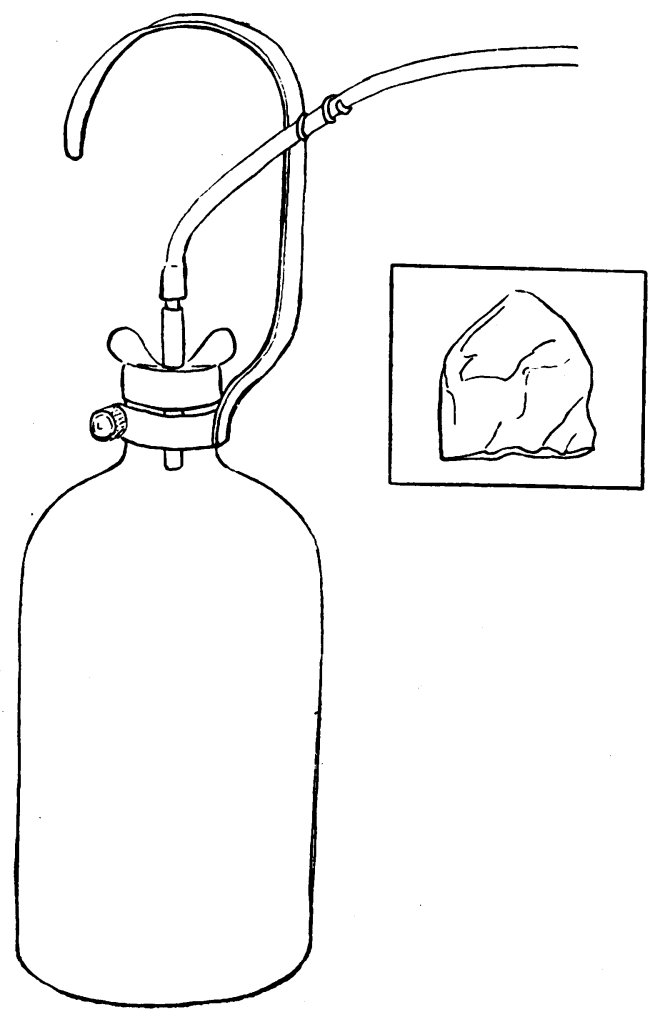

FIG. I.-Modified Mayo Clinic urine collecting bottle. The inset shows a viscocap.

has not been done already, and prompt corrective measures taken if necessary. Vasectomy is often done at this stage if the patient is over 70.

Free administration of fluids is highly desirable in uraemic cases, but the urologist must be guided in this most important matter by his medical associates; for instance, forcing fluids into a patient with congested lung bases can only harm both lungs and kidneys. Uraemia is often associated with anaemia of sufficient significance to need blood transfusion for its rapid correction.

The patient needing pre-operative medical treatment is prepared for operation as rapidly as possible, and my medical associate, Dr. Mayne, notifies me when maximum improvement has been effected. In dealing with the uraemic patient we follow Thompson (1939) and do not wait till the blood urea is normal, but operate when it starts to fall, which almost always coincides with diuresis. Unless the patient's kidneys have been irreparably damaged, the blood urea will begin to fall within a week or two, though in some cases it may never again reach a normal level.

\section{What Operation Should be Performed ?}

I would like straight away to condemn per- manent cystostomy. In my experience permanent cystostomy inflicts much suffering and misery on only too many ; if done at all, it should be reserved for the phlegmatic and well-to-do. The urologist worthy of the name must attack the obstruction itself.

In cases of adenomatous enlargement I have performed in my time Freyer's operation in one and two stages, Thomson Walker's operation with and without immediate closure, Wilson Hey's excellent operation, and Millin's retropubic approach, to complete the list of 'open' operations. I have no practical experience of Young's perineal prostatectomy. Last March Mr. Ogier Ward kindly demonstrated his vesiculo-capsular method to me at St. Peter's Hospital. As Ward points out, the indications for this procedure are limited, and I have not yet had an opportunity of trying it myself. In the transurethral fields I began by using the Stern-Davis McCarthy resectoscope, but since visiting the Mayo Clinic in 1938 have employed only Gershom Thompson's 'cold punch.'

My present practice is to use Freyer's operation for the patient with a large gland and a low cystostomy. All other cases are dealt with either by the cold punch or retropubically. Counting for the moment the fibrous and carcinomatous obstructions as well as the adenomatous, I use both methods roughly to an equal extent. It is important to distribute the material so that both operations are performed sufficiently often to enable efficiency to be not only maintained but, if possible, increased. This is a great change from the procedure of some years ago, when I resected $100 \mathrm{gm}$. at a sitting and performed endoscopic resection on 80 per cent. or so of all cases. At present I am endeavouring to limit the use of the punch in adenomatous cases to those only needing 20-30 gm. resections. Although I still, and will always, prize the punch, my change over from it is based on reasons already given elsewhere. Because of the difficulty of assessing the size of the enlarged prostate, the operator who follows a similar policy must keep well within his maximum resecting ability, unless he is prepared to face the prospect of many multiple 45 -minute resections. It is well known that it is not safe to prolong transurethral resection much beyond 45 minutes.

Cysto-urethroscopy is not only a valuable method of excluding coincidental vesical pathology, but is also a splendid means of determining the size and configuration of the gland. It is often the only way of discovering the 'middle lobe.' With the cysto-urethroscope the length of the prostatic urethra and the increase, if any, in the internal urinary orifice in the sagittal plane can be accurately measured. The instrument will not, 
however, completely disclose expansions of the prostate in either the coronal or sagittal planes. Bimanual rectal examination alone can do this. Unfortunately bimanual palpation is quite often impossible, hence, when resecting, the surgeon must be prepared for a wide margin of error in his assessment of the size of the adenomatous gland. Lastly, in this connection, I agree with Millin (1947) that the time for cysto-urethroscopy is immediately before operation.

A proper appreciation of the indications for, and skill in the performance of all the modern operations can only be developed if a large amount of clinical material is available. If I were a general surgeon obliged to do an occasional prostatectomy, I would be a two-stage Freyer addict. I would begin my attack on the large gland obstruction with a stab cystostomy and maintain drainage for a week or two. Suprapubic drainage has a marvellous effect in reducing prostatic congestion, and the subsequent enucleation is so relatively bloodless that packing and the use of such contraptions as the Foley bag are rarely needed. As for the smaller prostates, I should search hard and earnestly for urological assistance, for the sake of the patient and my conscience.

The more skilled urologist, though occasionally compelled to fall back on Freyer's operation, will choose one of the modern methods because of their obvious advantages, in particular better haemostasis and speedier convalescence. It is clear that he must be able to use a resectoscope as well. Obviously, each man will use the methods that suit him and his circumstances. If the choice is wisely made I feel sure that good men backed by good organization, using any of the modern techniques, open or transurethral, will get comparable results.

For my part I discarded the Harris and Wilson Hey techniques in favour of the Millin because the retropubic suited me better. For one thing I could do it in about half the time needed by me for either of the other two. Similarly, having given diathermic resection a trial, I now use only Thompson's punch, because it gives me better differentiation between adenomatous tissue and the capsule, better haemostasis and faster cutting. I believe a properly performed punch (or, for that matter, diathermic) resection is as efficient and as permanent as any other ' prostatectomy' and also safer. 'Prostatectomy' is put in inverted commas because it is a misnomer; in adenomatous disease, adenomatous tissue only and not the prostate itself is removed. The present plan of limiting punch resections to 20-30 gm. glands was decided on only after much thought and consideration, and the decision was undoubtedly influenced by Millin's argument that even for the patient's sake the surgeon should think of himself. No surgical procedure is more exhausting both mentally and physically than the resection of a large prostate; at one and the same time it is both exacting and boring.

I now only do resections requiring the removal of more than $30-40 \mathrm{gm}$. in really bad cases, and even in them do Millin's operation if the mass exceeds $60-70 \mathrm{gm}$. This occasional extension of the use of the punch is a tribute to my faith in its greater safety.

Analysis of Total Number of Prostatic Cases OPERATED ON FROM OCTOBER, 1946-AUguST, 1948

\begin{tabular}{|c|c|c|c|}
\hline Type of Operation & Cases & Deaths & $\begin{array}{l}\text { Per } \\
\text { Cent. }\end{array}$ \\
\hline Punch Resection $\quad \ldots \quad \ldots$ & 324 & 9 & 2.8 \\
\hline $\begin{array}{l}\text { Suprapubic Prostatectomy } \\
\text { with closure (modified } \\
\text { Thomson-Walker) }\end{array}$ & 26 & $I$ & 3.8 \\
\hline Retropubic Prostatectomy & 133 & 8 & \\
\hline Wilson Hey Prostatectomy... & $\mathbf{2 I}$ & $\mathbf{I}$ & 4.8 \\
\hline Freyer Prostatectomy $\quad$. & 5 & - & - \\
\hline Total & 509 & 19 & $3 \cdot 7$ \\
\hline
\end{tabular}

N.B.-Permanent cystostomy was done on less than 0.5 per cent. of total admissions.

It is only fair to point out that the $\mathrm{I} 33$ retropubic operations are my first 133 such operations. The 324 punch resections have behind them the experience of well over 1,000 of these operations. During 1946-47 bad risk cases, almost regardless of the size of the prostate, were treated by endoscopic resection.

\section{Notes on Technique \\ Second-Stage Freyer}

We (my assistants and myself) excise the original wound and fistula, and free the bladder from the abdominal wall. A short incision is made in the bladder wall downwards from the lower edge of the fistula ; this, of course, safeguards the peritoneum. The adenomatous tissue, nearly always considerable in amount, is enucleated with the help of rectal counter-pressure given by the second assistant. A pair of von Lichtenberg's retractors are then inserted and the adenomatous mass, as it lies free in the bladder, is visualized. It is then extracted with Hobday's bitch forceps, a veterinary instrument used in canine midwifery practice (Fig. 2). If both lateral lobes are markedly enlarged, each is enucleated in turn. When these are grossly enlarged, the proximal part of each is enucleated and then seized with Hobday's forceps, traction on which makes enucleation of the distal 


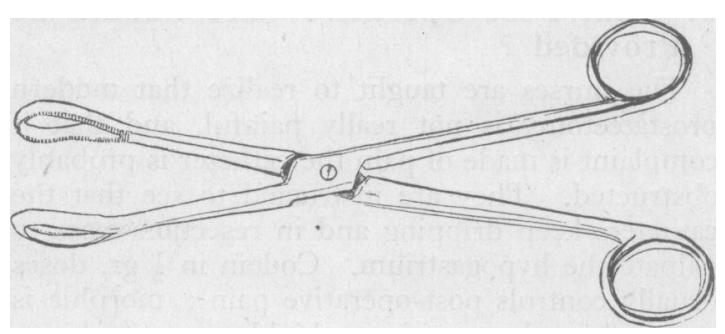

Fig. 2.-Hobday's forceps. They are more curved on the flat than shown in this sketch. It may be an advantage to provide the handles with a ratchet.

part easier. Enucleation completed, the patient is put in the Trendelenberg position, von Lichtenberg's and Morson's retractors put in position, and with the aid of a spotlight and scissors, tags and remnants visualized and cut away. In our experience the second-stage Freyer is relatively bloodless and we use neither packing nor the Foley bag. A No. 20 or No. 22 Harris, or McCarthy electrotome catheter is passed per urethram and stitched in by Wilson Hey's method. The bladder is closed round a No. 30 or No. 35 Malecot, which is removed usually in two or three days. The urethral catheter with luck may be dispensed with in a week or so.

\section{Retropubic Prostatectomy}

It is remarkable how satisfactory this operation is in the obese. We occasionally use the transverse, but more often than not the low short vertical incision. If, in suturing the latter, two or three figure of eight silkworm tension sutures are placed, subsequent ventral herniation is very exceptional. We follow Millin's technique with a few minor exceptions. Like him we coagulate large veins in the pre-prostatic fat; subsequent section of these vessels greatly facilitates displacement of the fat. In easy cases we dispense with the lateral packs. Instead of a stay stitch to steady the capsule, we use a bullet forceps inserted a millimeter or so from the line of the capsular incision. The capsular incision is conveniently made with a long-handled knife. When the capsular incision is completed a stay stitch is placed through the middle of its lower edge or flap and the bullet forceps and rongeur removed. We have given up the use of the T clamps, and use long Spencer Wells to control bleeding points. They are by no means always needed. We occasionally succeed in sectioning the urethra under vision. We find Hobday's forceps helpful in extracting moderate-sized and large masses; Jacob's uterine vulsellum is also useful, particularly in the smaller cases; Luc's septum forceps are amazingly helpful in removing small, encapsulated adenomatous 'seeds' adhering to the capsule after the removal of the main ' tumour,' also for putting traction on tags prior to their scissors' resection, and occasionally for guiding the catheter into the bladder. We always palpate the interior of the bladder and realize the need for careful inspection of the prostatic cavity to ensure complete removal of all tissue needing removal. In dealing with the bladder neck, we base our work on Millin's practice. The closure of the capsular incision is commenced by inserting a stitch at its extreme left-hand end. This stitch is useful both as a guide and as a tractor. The standard continuous stitch is then carried from right to left until the stay stitch in the middle is reached. The boomerang needle is used to thread this through the upper edge of the incision and it is then tied and cut off. The long stitch is then continued in the usual way until the left hand of the capsular wound is reached. While recognizing the importance of firm and accurate stitching, we believe that too tight a closure is prejudicial to primary healing. We usually remove the urethral catheter permanently in four or five days.

\section{Punch Resection}

In addition to the smaller adenomatous lesions, this is the only operation used by me for the fibrous gland and for the carcinomatous obstruction which does not yield to hormone treatment. We often use Thompson's (1934) modification of his operation for the smaller stone-bearing prostate. Except when the perineal approach is used, we work exclusively with the 27 French instrument.

Two important developments must be reported. The first of these, the use of isotonic solutions instead of water, is applicable to the diathermic method also. Based on observations by Creevy (1947), Foley, Emmett, McLaughlin and others, it has, in my experience, transformed the convalescence of patients and completely removed the risk of oliguria, which once or twice in a year's work might end in a fatal, untreatable anuria. The underlying cause of the trouble is " the haemolysis of the patient's blood by the entrance into the venous system of the sterile water used as an irrigating fluid during operation.' We use 4 per cent. glucose solution which is sterilized in a suitable 12-gal. sterilizer, mounted $3 \mathrm{ft}$. 8 in. above the top of the operating table. The solution is replenished daily as required, but at the end of each week the tank must be emptied completely. The operator accustomed to water will find glucose enhances his difficulties for a while, but with a little practice these troubles disappear as completely as the risk of oliguria. Jessop and I (1948) have confirmed Creevy's observation that 


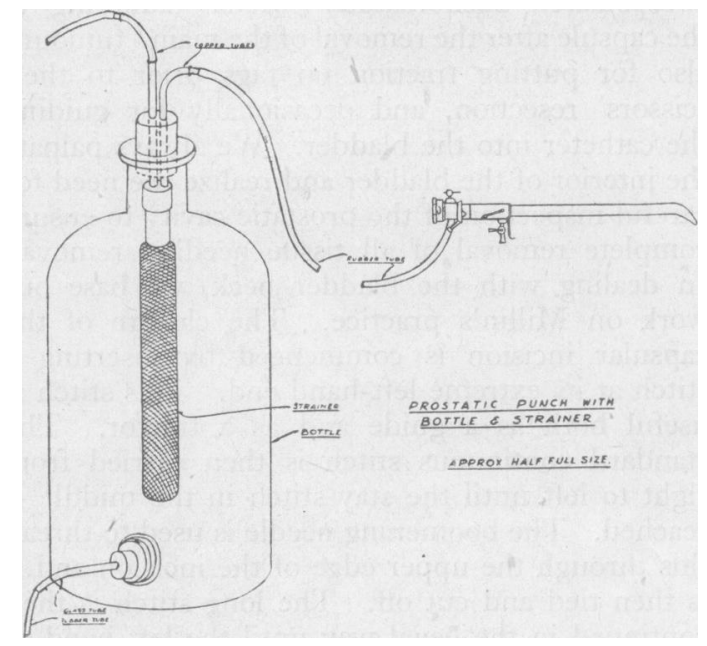

FIG. 3.-Suction apparatus. The bottle holds 5 gal. which is quite adequate if resections are limited as described in the text. The outlet shown is quite unnecessary and actually too slow in operation. The rubber tubing used is transparent latex.

the patient's blood sugar may, in some cases, be markedly elevated. The rise is, however, quite temporary, and next day the level is invariably normal. The use of glucose is not contraindicated in the diabetic patient, provided he is controlled as found necessary by immediate pre- and postoperative blood sugar estimations.

The second development is the use of suction applied to the outlet of the Thompson punch. I think this was first described in a letter to the Urologists' Correspondence Club dated March I 5, 1948, by Charles Fiel of Lubbock, Texas, who ascribed it to Keller Dos of Fort Worth. The special apparatus needed is shown in Fig. 3. I use continuous suction from a suction apparatus made for me by Mr. Blease of Liverpool. A negative pressure of 25-30 lb. is employed. Not only is the emptying of the bladder greatly accelerated, but in all cases the amount of tissue remaining in the bladder is diminished and in many cases the extraction is complete. At the moment the bladder is sucked empty a waterfalllike effect appears at the window of the punch. Complete tissue extraction is not favoured by the presence of a cystostomy.

I am indebted to Mr. Arnold Kleine, of the American Cystoscope Makers, for the valuable information that, in arresting haemorrhage, instead of applying the electrode actually on to the bleeding spot, making it just touch the jet of the spurter is speedier and more efficient.

\section{What Post-Operative Care Should be Provided ?}

The nurses are taught to realize that modern prostatectomy is not really painful, and that if complaint is made of pain the catheter is probably obstructed. They are instructed to see that the catheters keep dripping and in resection cases to palpate the hypogastrium. Codein in $\frac{1}{2}$ gr. doses usually controls post-operative pain ; morphia is reserved for the sensitive or highly-strung subject. The patient is given fluids freely by mouth or, if necessary, intravenously. Bladder washouts and irrigations are employed in both retropubic and resection cases only if the catheter becomes obstructed. Most cases do not need them at all, but if necessary normal saline or glucose is the irrigating fluid used. Blood is transfused when required, usually after a haemoglobin estimation and red cell count.

\section{What Special Conditions Arise in the Case of Carcinoma ?}

\section{Notes on Diagnosis}

While digital rectal examination is the best clinical means of diagnosis, there are some pitfalls :-

I. The most obvious of these is the stonebearing prostate. An X-ray film which shows no calculi simplifies the situation. If stones are present an absolute diagnosis may be very difficult indeed. It must be remembered that the presence of calculi does not in any way render the gland less liable to malignancy.

2. Cancer may be present in a very moderately enlarged gland, normal in mobility and consistency. I meet a few of these every year. Fortunately they fall into the group reserved for punch resection, and in those so treated the diagnosis, which nearly always comes as a surprise, is made by the pathologist. Carcinoma, except in some cases in its terminal stages or when complicating adenomatous disease, rarely gives rise to marked enlargement. Short duration of symptoms and minimal enlargement of the gland justify suspicion of malignancy, even if the consistency and mobility are normal. The administration of stilboestrol in adequate dosage will settle the matter in some of these cases, because of rapid symptomatic improvement and rapid shrinkage in size of the prostate.

3. Gershom Thompson (personal communication) has pointed out that the presence of a large residual urine, with its resultant congestion of the prostate, will mask the hardness of the gland. If palpation is to be trustworthy, rectal examination must be deferred until the bladder has been relieved by an indwelling catheter for some days. 
4. Rectal examination owes its importance to the fact that carcinoma begins in, and may for a long while be limited to, the posterior lamella of the gland. It is for this reason that it is perfectly possible to remove by endoscopic resection enough tissues to relieve the patient, and still not cut deep enough to establish the diagnosis histologically.

5. In my experience abnormal elevation of the serum acid phosphatase is not only useful in the treatment of the established case, but now and again extremely helpful in the elucidation of the difficult one.

\section{Notes on Treatment}

\section{Hormone}

Huggins (I94I) did magnificent work when he instituted, on a well-reasoned foundation, hormonal treatment of this cancer. To appreciate what he has done it is necessary to look back to the days when Charles Mayo (1932) said, 'Whatever one does for the patient with carcinoma of the prostate gland, one is certain to be wrong,' and to the painstaking study by Bumpus (1926) who showed that when metastasis was not found at the first examination the average length of survival from that date was a year, but that if metastases were then present two-thirds of the patients were dead within nine months. The average duration of life from the first symptoms was 31 months in untreated cases. In my own experience, prior to Huggins' work, cases resected because of carcinomatous obstruction only too often, and in too short a time, needed re-resection. Re-resection is rarely called for today.

The synthesis of stilboestrol by Dodds in 1937 was a great step forward. For several years now we have reserved bilateral orchidectomy for the very occasional patient who cannot be trusted to continue taking stilboestrol, or for the equally rare individual who is totally intolerant of the drug. The initial dose is $20-30 \mathrm{mgm}$. daily, and the smallest maintenance dose is $5 \mathrm{mgm}$. per day. In a proportion of cases the drug is given every alternate week. This plan has possible theoretical and obvious economic advantages, and in most cases is just as efficient as continuous administration. It is particularly helpful to the patient who develops sore or painful breasts, as it materially reduces the severity and continuity of this trouble. I have not followed Reed Nesbit (1944) in withholding treatment until 'the onset of symptoms arising from advanced or metastatic lesions.' As is now well known, dienoestrol is much less efficient than stilboestrol.

\section{Radiation}

In my experience an occasional case that fails to respond to stilboestrol or, which having responded for a while is again found to have prostatic hardness and fixity, may be benefited by deep $\mathrm{X}$-ray treatment. If stilboestrol fails to relieve the pain of osseous metastases, small dosage X-ray treatment may give a few months' relief. Cancerous glands which have been radiated seem to respond to hormone treatment just as well as those never exposed to the X-ray.

\section{Palliative Operations}

These become necessary when speedy relief of obstruction is essential, or when hormone therapy either fails completely to relieve obstruction or only relieves it to an inadequate degree. The best palliative operation is transurethral resection, for which permanent cystostomy is a miserable substitute.

\section{Radical Operations}

I have no practical experience here, and can only hope that general experience of Millin's radical retropubic procedure will be much better than general experience of Young's total perineal prostatectomy.

\section{Prognosis}

Creevy (1948) summed up the situation in these two sentences :- Results of palliative therapy are extraordinarily difficult to evaluate concisely because the best criterion is the prolongation of comfortable life and this is difficult to tabulate. Moreover, no one has yet had time to accumulate any sizeable series of cases followed up for a minimum of five years.' Creevy then quotes Nesbit's report that almost 70 per cent. of 783 patients treated before $194^{\circ}$ were dead within two years of diagnosis. He then points out that of 569 patients treated by castration, oestrogens, or both, by Vest and Frazier, Greene and Emmett, Herger, Sauer and Huggins, only 30 per cent. were dead by the end of the second year. 'That is,' he concludes, ' about half the patients who might have died without endocrine therapy were still living.'

I have not reviewed my own cases yet, but have no doubt at all of the general value of hormone treatment, though admitting that disappointing relapses and occasional total failures must be faced.

A recent review of 23 cases treated by orchidectomy in the first eight months of 1942, and described in the Lancet in February, 1943, shows that the results in Dublin tally closely with those obtained 'by Huggins (1946) in Chicago. Excluding two in whom the lesion was almost certainly vesical carcinoma, four of the remaining $2 \mathrm{I}$ are still alive, and three of them in good health. The 
fourth case, examined recently, was found to have good urinary function, mild anaemia and no X-ray evidence in the bony pelvis, vertebrae or lungs of metastases, though secondaries must be present because his serum acid phosphatase is 17 units. Of the cases that did not survive, death in many was not due to prostatic cancer.

\section{BIBLIOGRAPHY}

BAILEY, H. (1934), Brit. F. Surg., 6, 225.

BUMPUS, H. C. (1926), Surg. Gyn. E Obst., 43, 150. CHAPMAN, T. L. (1949) Lancet, 1, 502. CREEVY, C. D. (1947), Ұ. Urol., 58, 125.

CREEVY, C. D. (1948), f. Am. Med. Assoc., 138, 412.

DOYEN, E. (r917), 'Surgery, Therapeutics and Operative Technique,' Eng. Ed., 1, 16.

EMMETT, J. (1943), f. Urol., 49, 815.

HUGGINS, C., and HODGES, C. V. (1941), Cancer Research, r, 293.

HUGGINS, C. (1946), Ұ. Am. Med. Assoc., 131, 576.

HUNT, V. C. (1923), Collected Papers, Mayo Clin., p. 505.
JESSOP, W. E. J., and LANE, T. J. D. (1948), Irish F. Med. Sci., Nov., 1948.

KIDD, F. (1927), cit. BAILEY, H. (1934), Brit. F. Surg., 6, 225 MAYO, C. H. (1932), cit., BUMPUS, H. C., 'Minor Surg. of Urinary 'Tract,' p. 55.

MILLIN, T. (1947a), Irish F. Med. Sci., May, 1947.

MILLIN, T. (1947b), 'Retropubic Urinary Surgery,' Edinburgh, E. \& S. Livingstone Ltd., p. 65.

MILLIN, T., MCALLISTER, C. L. O., KELLY, P. M. (1949), Lancet, 1,381 .

MOORE, R. (1935), F. Urol., 33, 224.

MORSON, C. (1935), Post Grad. Med. F., 11, 437.

MORSON, C. (1946), Brit. Med. f., I, 888.

MOTHERSILL, G. S., and MORSON, C. (1921), 1, 418.

NESBIT, R., and CUMMINGS, R. H. (1944), F. Am. Med. Assoc., 124, 180 .

RICHES, E. W. (1943), Brit. F. Surg., 31, 135.

RICHES, E. W. (1944), Proc. Roy. Soc. Med., 37, 22.

RICHES, E. W. (1949), Brit. Med. F., 1, 888.

THOMPSON, G. (1934), Collected Papers, Mayo Clin., 26, 341.

THOMPSON, G. (1939), Proc. Staff. Meet. Mayo Clin., 401.

VERNON, H. K. (1949), Lancet, 1, 547.

WILSON HEY, H. (1945), Brit. F. Surg., 33, 4r.

WILSON HEY, H. (1948), 'Textbook of Genito-Urinary Surgery,' ed. H. P. Winsbury-White. Edinburgh, E. \& S. Livingstone Ltd., p. 477. .

VON ZWALENBEIRG, C. (1920), Ұ. Am. Med. Assoc., 75, 17 I 1 . 